\title{
Clinical characteristics and therapeutic analysis of 51 patients with Marjolin's ulcers
}

\author{
RUI SHEN ${ }^{1,2}$, JINMING ZHANG ${ }^{1}$, FENGGANG ZHANG ${ }^{2}$, YONGJUN DU ${ }^{2}$, WEIQIANG LIANG ${ }^{1}$, \\ LUSHENG XU ${ }^{2}$, XUELIANG DU ${ }^{2}$, PING $\mathrm{CHEN}^{2}$ and XIAODONG $\mathrm{CHEN}^{2}$
}

\author{
${ }^{1}$ Department of Plastic Surgery, The Second Affiliated Hospital of Sun Yat-sen University, Guangzhou, Guangdong 510120; \\ ${ }^{2}$ Department of Plastic Surgery, The Affiliated Foshan Hospital of Sun Yat-sen University, \\ Foshan, Guangdong 528000, P.R. China
}

Received February 21, 2014; Accepted July 1, 2015

DOI: 10.3892/etm.2015.2699

\begin{abstract}
Marjolin's ulcers, which are epidermoid carcinomas arising on non-healing scar tissue, may be of various pathological types, including squamous cell carcinoma. The pathogenesis of squamous cell carcinoma arising in an ulcer differs from that of the primary cutaneous squamous cell carcinoma. This squamous cell carcinoma is aggressive in nature, and has a high rate of metastasis. Between January 2001 and September 2013, 51 patients with Marjolin's ulcers were admitted to the Departments of Plastic Surgery of the Affiliated Foshan Hospital and the Second Affiliated Hospital of Sun Yat-sen University. The ulcers included 43 cases of squamous cell carcinoma, six of melanoma, one of basal cell carcinoma and one of epithelioid sarcoma. The clinical data of these patients were retrospectively analyzed. Patients were followed until mortality. Among the patients with squamous cell carcinoma, $30.23 \%$ exhibited sentinel lymph node metastasis and $11.63 \%$ had distant metastasis. Among the patients with melanoma, $66.67 \%$ had sentinel lymph node metastasis and $33.33 \%$ had distant metastasis. Sentinel lymph node metastasis was successfully detected in 11 patients with Marjolin's ulcer using ${ }^{18} \mathrm{~F}$-fluorodeoxyglucose positron emission tomography-computed tomography and B-mode ultrasound guided biopsy. Squamous cell carcinoma was often treated by extended resection and skin grafting or skin flap repair. Patients with deep, aggressive squamous cell carcinoma of an extremity and sentinel lymph node metastasis underwent amputation and lymph node dissection. This treatment was also used for melanoma type Marjolin's ulcers.
\end{abstract}

Correspondence to: Dr Rui Shen, Department of Plastic Surgery, The Affiliated Foshan Hospital of Sun Yat-sen University, 81 Lingnan Street North, Foshan, Guangdong 528000, P.R. China E-mail: shenruihaohao@163.com

Key words: Marjolin's ulcer, squamous cell carcinoma, sentinel lymph node, chronic skin ulcer, metastasis, ${ }^{18} \mathrm{~F}$-fluorodeoxyglucose positron emission tomography-computed tomography

\section{Introduction}

Jean Marjolin first described malignant change arising in a skin ulcer in 1828 . This condition was subsequently described by Smith in 1850 and Da Costa in $1903(1,2)$. As these ulcers have not been extensively studied, the mechanisms underlying carcinomatous change remain unclear. Marjolin's ulcers are frequently induced by scarring following deep burns caused by hot ceramic, metal or soil (3-5). Marjolin's ulcers are usually considered to be highly aggressive tumors, with a rapid rate of regional metastases. Radical excision is the primary treatment option; however, there is currently no consensus regarding the efficacy of lymph node dissection. Marjolin's ulcers are typically associated with a poor prognosis, and may be life threatening. As living standards improve, the incidence of Marjolin's ulcers should gradually decrease. Although there are few reports of patients with Marjolin's ulcer in China (6), this is not a rare disease, even in the relatively well-developed Pearl River Delta region. The Departments of Plastic Surgery of the Affiliated Foshan Hospital (Foshan, China) and the Second Affiliated Hospital (Guangzhou, China) of Sun Yat-sen University, located in the Pearl River Delta region, treated 51 patients with Marjolin's ulcers between January 2001 and September 2013.

\section{Materials and methods}

Patients and data collection. Fifty-one patients who were treated for Marjolin's ulcers between January 2001 and September 2013 were retrospectively reviewed. Follow-up was continued for more than one year. The diagnoses were verified by incisional biopsies in all cases. The specimens received by our laboratory were fixed by formalin and processed using routine hematoxylin and eosin staining. Data collected included age, gender, time from initial ulceration to carcinomatous change, cause of initial ulceration, history of ulcer treatment, surgical treatment and follow-up results. The associations between pathological type and metastasis and between the location of squamous cell carcinoma and metastasis were analyzed. Eleven patients with deep, aggressive squamous cell carcinoma or melanoma and suspected sentinel lymph node metastasis underwent ${ }^{18} \mathrm{~F}$-fluorodeoxyglucose positron 
Table I. Metastasis according to the pathological type of Marjolin's ulcer.

Patients with sentinel

Pathological type lymph node metastasis, n (\%)
Patients with

distant metastasis, n (\%)

\begin{tabular}{lrr}
\hline Squamous cell carcinoma & 43 & $13(30.23)$ \\
Melanoma & 6 & $4(66.67)$ \\
Basal cell carcinoma & 1 & $0(0.00)$ \\
Epithelioid sarcoma & 1 & $0(0.00)$
\end{tabular}

$5(11.63)$

$2(33.33)$

$0(0.00)$

$0(0.00)$

Table II. Sentinel lymph node and distant metastases according to the location of squamous cell carcinoma.

\begin{tabular}{lrrr}
\hline Location & $\mathrm{n}$ & Sentinel lymph node metastasis, $\mathrm{n}(\%)$ & Distant metastasis, $\mathrm{n}(\%)$ \\
\hline Lower limb & 31 & $11(35.48)$ & $5(16.13)$ \\
Upper limb & 7 & $2(28.57)$ & $0(0.00)$ \\
Head & 4 & $0(0.00)$ & $0(0.00)$ \\
Chest & 1 & $0(0.00)$ & $0(0.00)$ \\
\hline
\end{tabular}

emission tomography-computed tomography (PET-CT) and B-mode ultrasound-guided biopsy, with a $100 \%$ accuracy rate, for the detection of sentinel node metastasis. This retrospective study was approved by the ethical review boards of the participating instututions and written informed consent was obtained from all patients or their next of kin.

\section{Results}

Patients. The 51 patients with Marjolin's ulcers included 22 males $(43.14 \%)$ and 29 females $(56.86 \%)$ with a mean age of 64.15 years (range, 32-89 years). The mean time from initial ulceration to diagnosis of squamous cell carcinoma was 13.42 years (range, 6 months-54 years) and to diagnosis of melanoma was 2.47 years (range, 3 months-10 years). One patient developed epithelioid sarcoma after two years and one developed basal cell carcinoma after three years. Squamous cell carcinomas were located on the lower limb in 31 cases, the upper limb in seven cases, the head in four cases and the chest in one case. The six cases of melanoma were all located on the foot. One case of basal cell carcinoma was located over the occipital area and one case of epithelioid sarcoma was located on the foot.

The underlying injury causing ulceration was a burn scar in 35 cases and a traumatic wound scar in 16 cases. Ulceration was usually present for a long time prior to carcinomatous change. The non-healing of ulcers was associated with ineffective initial treatment. Of the 51 patients, seven $(13.73 \%)$ received treatment in a large general hospital, eight $(15.69 \%)$ received conservative treatment in the outpatient clinic of a community hospital, $23(45.10 \%)$ received external application of Chinese herbs at home and 13 (25.49\%) did not receive any treatment.

The pathological type was squamous cell carcinoma in 43 cases $(84.31 \%)$, including 42 cases of well-differentiated squamous cell carcinoma (Broder's Grade I) and one case of moderately differentiated squamous cell carcinoma (Broder's
Grade II), melanoma in six cases (11.76\%), basal cell carcinoma in one case and epithelioid sarcoma in one case. The rate of metastasis varied among the pathological types. In patients with squamous cell carcinoma, the rate of sentinel lymph node metastasis was $30.23 \%$ and the rate of distant metastasis was $11.63 \%$. In patients with melanoma, the rate of sentinel lymph node metastasis was $66.67 \%$ and the rate of distant metastasis was $33.33 \%$. Lymph node and distant metastasis were not detected in the patients with basal cell carcinoma and epithelioid sarcoma (Table I).

The rates of lymph node metastasis and distant metastasis in patients with squamous cell carcinoma varied according to the location of the lesion. In patients with squamous cell carcinoma of the lower limb, the rate of sentinel lymph node metastasis was $35.48 \%$ and the rate of distant metastasis was $16.13 \%$. In patients with squamous cell carcinoma of the upper limb, the rate of sentinel lymph node metastasis was $28.57 \%$ and the rate of distant metastasis was $0 \%$ (Table II). Eleven patients with squamous cell carcinoma and two patients with melanoma with deep, aggressive tumors and suspected sentinel lymph node metastasis underwent ${ }^{18} \mathrm{~F}$-fluorodeoxyglucose PET-CT and B-mode ultrasound guided biopsy. These investigations had a $100 \%$ accuracy rate for the detection of metastasis (Table III).

Surgical methods and follow-up results. One patient with basal cell carcinoma on the head underwent extended resection and skin grafting, with no evidence of relapse or metastasis after eight years of follow-up. One patient with an epithelioid sarcoma over the occipital region underwent extended resection and skin grafting, with no evidence of relapse or metastasis after seven years of follow-up. Of the 43 patients with squamous cell carcinoma, 27 did not develop aggressive tumors or sentinel lymph node metastasis. These 27 patients underwent extended resection and skin grafting or skin flap repair. One of these patients succumbed to extensive metastasis after three years. Five patients developed deep, aggressive tumors 


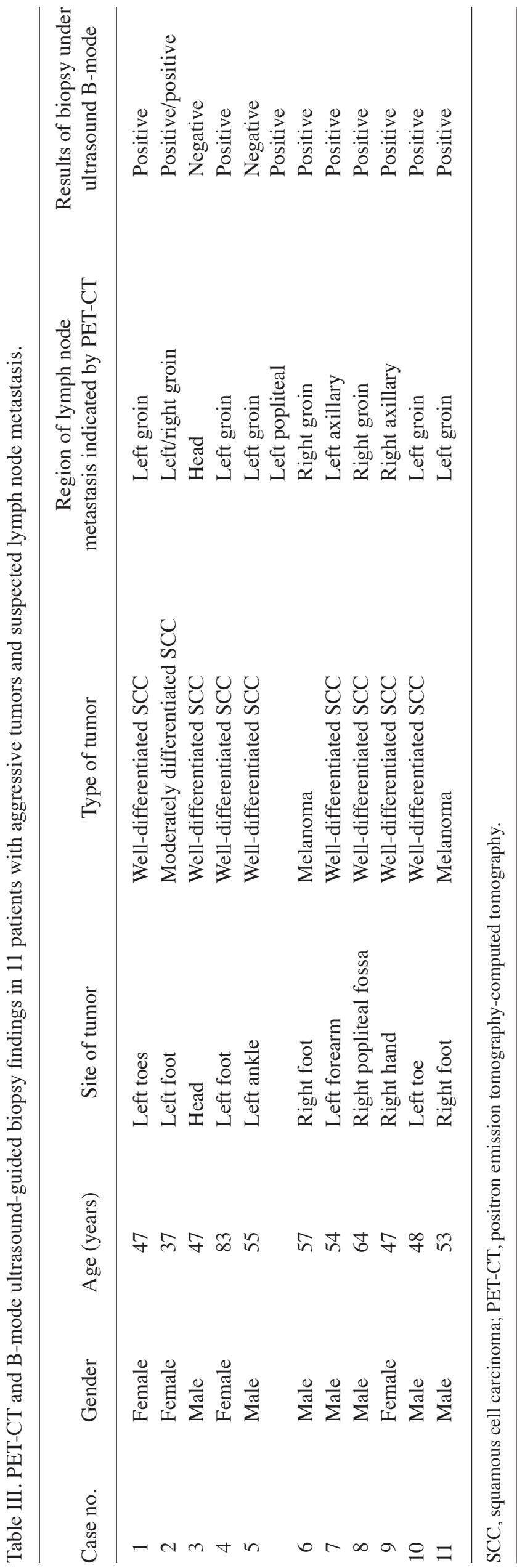

with no metastasis. Four of these five patients underwent amputation and survived. One patient refused amputation and underwent only resection of the ulcer and surrounding tissues with skin grafting, and subsequently developed metastasis and succumbed one year later. Eleven patients developed deep, aggressive squamous cell carcinoma with inguinal, popliteal or axillary sentinel lymph node metastasis. Nine of these 11 patients underwent amputation and sentinel lymph node dissection, and eight patients survived. One patient who underwent amputation and inguinal lymph node dissection succumbed two years later due to pelvic lymph nodes and lung metastasis. One patient refused surgery and developed metastasis, and succumbed two years later. One patient developed deep, aggressive squamous cell carcinoma with extensive sentinel lymph node metastasis and distant pelvic lymph nodes metastasis. Radiotherapy was administered instead of surgery and the patient succumbed one year later due to lung metastasis (Table IV).

Two of the six patients with melanoma succumbed. One patient with melanoma on the right foot, right inguinal lymph node metastasis and lung metastasis was considered to have unresectable disease and received interferon therapy, and one patient with melanoma on the left foot and left inguinal lymph node metastasis refused surgery. These two patients succumbed from lung metastasis six months later. The other four patients survived. Two of these four patients did not develop metastasis, and underwent extended resection and skin grafting or skin flap reconstruction. The remaining two patients with melanoma on the foot and inguinal lymph node metastasis underwent extended resection and skin grafting or amputation combined with inguinal lymph node dissection, and survived with no evidence of relapse or metastasis (Table V).

A number of patients had unusual presentations of disease. In one patient, squamous cell carcinoma developed simultaneously in traumatic skin ulcers on the lateral and medial sides of the left ankle. One patient developed squamous cell carcinoma in a burn scar ulcer over the temple, which extended through the bone and dura mater into the brain (Fig. 1). Three patients developed squamous cell carcinoma in an ulcer on the finger (Fig. 2).

Case report. A 55-year-old male with a 20-year history of ulceration over the lateral and medial aspects of his left ankle presented with a two-month history of pain. In 1993, he had developed chronic ulceration on either side of the ankle from friction caused by his shoe. The wounds were originally treated with saline irrigation by a rural doctor. The patient worked in a paddy field and had poor economic circumstances.

Physical examination revealed a $4.5-\mathrm{cm}$-diameter ulcer over the medial aspect and a 5-cm-diameter ulcer over the lateral aspect of the left ankle. A Marjolin's ulcer with similar histological characteristics occurring in different parts of the body simultaneously is a rarely reported occurrence. The crater-shaped ulcers were dirty, necrotic and malodorous, with surrounding tissue proliferation (Figs. 3 and 4).

Radiography showed areas of dense cortical bone and new periosteal bone formation in the middle and distal parts of the left tibia and fibula, and in the calcaneus and talus. There was a small area of bone destruction in the distal part of the tibia, 


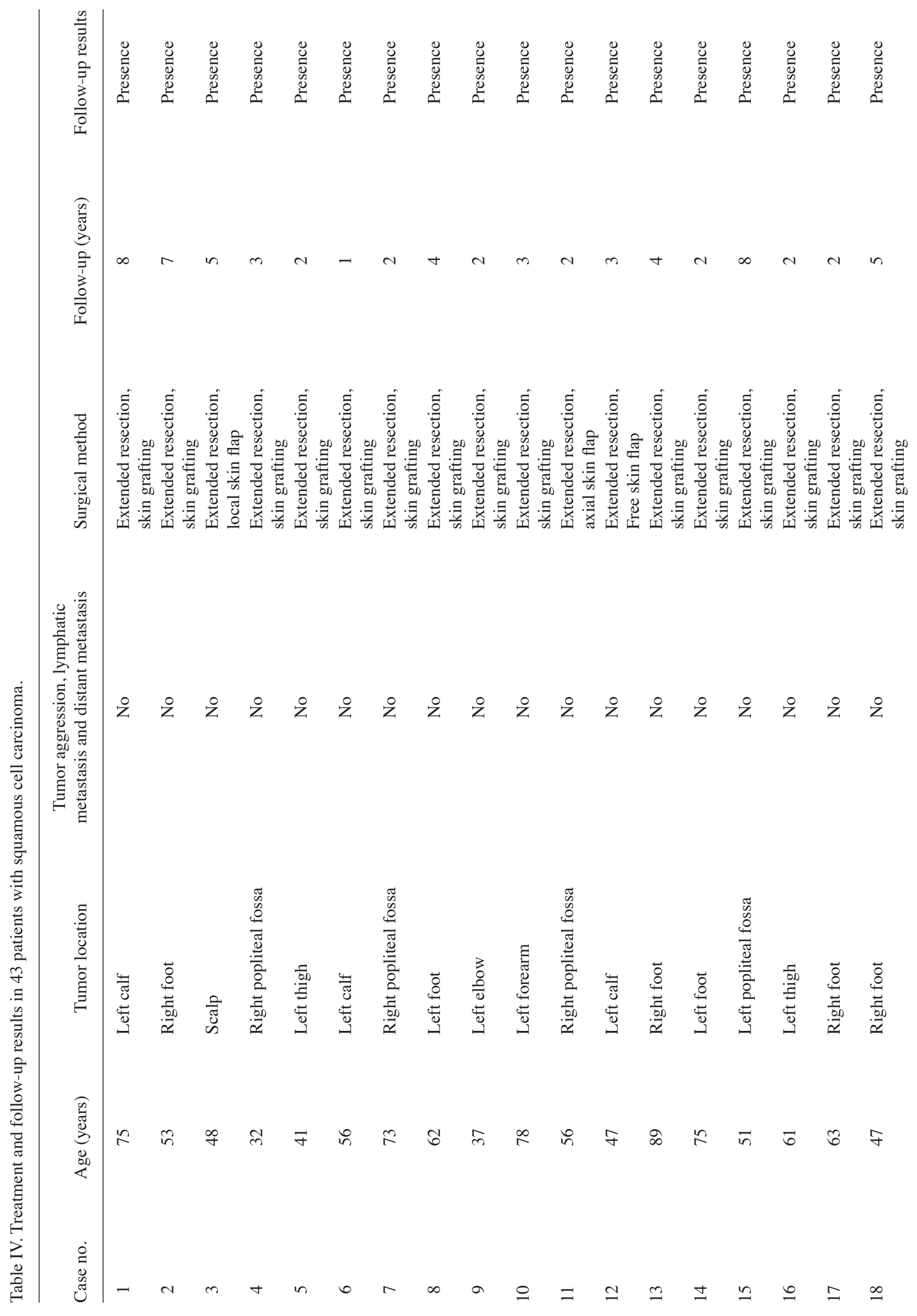




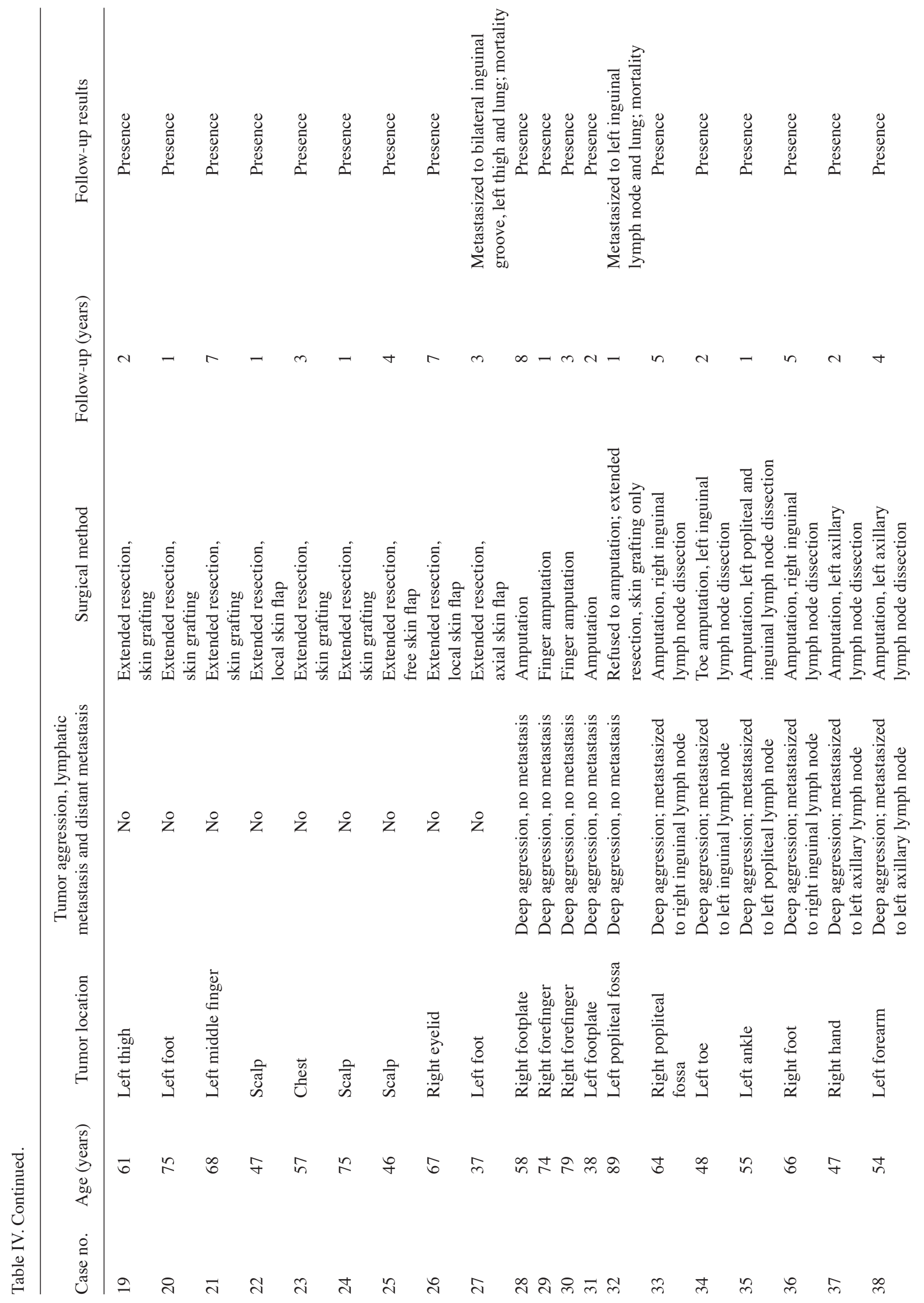


with signs of chronic osteomyelitis and surrounding soft tissue swelling (Fig. 5). Bacterial cultures of the wound surface revealed Proteus penneri.

In September 2012, the patient underwent partial resection of the lesions. Pathological examination showed well-differentiated squamous cell carcinoma in the two lesions (Fig. 6). PET-CT showed abnormal uptake in the lymph nodes of the left popliteal fossa and left inguinal region, but it was unclear whether this represented wound infection or tumor metastasis (Fig. 7).

In September 2012, the patient underwent below-knee amputation of the left leg for these aggressive lesions. Two weeks after surgery, PET-CT still showed increased uptake in the lymph nodes of the left popliteal fossa and inguinal region, indicating possible metastasis. The patient then underwent B-mode ultrasound-guided biopsy of the left popliteal and inguinal lymph nodes. Examination of the biopsy specimens showed metastasis in the popliteal nodes, but not in the inguinal nodes (Fig. 8).

The patient underwent left popliteal and inguinal lymph node dissection. Postoperative pathological examination showed metastatic squamous cell carcinoma in the popliteal nodes but not in the inguinal nodes, which was consistent with the previous biopsy findings. There was no evidence of relapse or metastasis after one year.

\section{Discussion}

Marjolin's ulcers are tumors that form in chronic skin ulcers, predominantly on burn scar wounds. These tumors also develop on other wounds, including pressure sores (7), venous stasis ulcers (8), traumatic wounds (9), osteomyelitis (10), fistulas (11), leprosy ulcers (12) and lacerations (13). Burn scars are reported to have a rate of carcinomatous change of $2 \%$ (14). The most common type of Marjolin's ulcer is squamous cell carcinoma, followed by basal cell carcinoma, sarcoma and melanoma $(15,16)$. Kowal-Vern and Criswell (17) retrospectively reviewed 412 cases of Marjolin's ulcers reported in 146 studies between 1923 and 2004, and found that 71\% had squamous cell carcinoma, $12 \%$ had basal cell carcinoma, $6 \%$ had melanoma, 5\% had sarcoma and 6\% had other tumors. The present study included 51 patients with Marjolin's ulcers, including $43(84.31 \%)$ with squamous cell carcinoma and six $(11.76 \%)$ with melanoma.

Kowal-Vern and Criswell (17) reported that the average period of ulceration prior to carcinomatous change was 31 years. The present study included more female $(56.86 \%)$ than male $(43.14 \%)$ patients. The mean period of ulceration prior to carcinomatous change was relatively short (13.42 years for squamous cell carcinoma and 2.47 years for melanoma). The rates of lymph node and distant metastasis are higher in squamous cell carcinoma-type Marjolin's ulcer than in primary cutaneous squamous cell carcinoma $(4,18)$. Kowal-Vern and Criswell (17) reported regional or sentinel lymph node metastasis in $22 \%$ of cases of squamous cell carcinoma-type Marjolin's ulcer, distant metastasis in 14\% and a resulting mortality rate of $21 \%$. Novick et al (19) reported a metastasis rate of 54\% from lower limb squamous cell carcinoma-type Marjolin's ulcer, including metastases to the brain, liver, lung, kidney and distant lymph nodes. In the present study, patients 
Table V. Characteristics of six patients with melanoma.

\begin{tabular}{|c|c|c|c|c|c|}
\hline Case no. & $\begin{array}{l}\text { Tumor } \\
\text { location }\end{array}$ & $\begin{array}{l}\text { Lymphatic and } \\
\text { distant metastases }\end{array}$ & Therapy & $\begin{array}{l}\text { Follow-up } \\
\text { (months) }\end{array}$ & Follow-up results \\
\hline 1 & Right foot & $\begin{array}{l}\text { Lung, right inguinal } \\
\text { lymph node metastasis }\end{array}$ & Interferon & 6 & $\begin{array}{l}\text { Lung metastasis; } \\
\text { mortality }\end{array}$ \\
\hline 2 & Left footplate & $\begin{array}{l}\text { Left inguinal lymph } \\
\text { node metastasis }\end{array}$ & Refused the treatment & 6 & $\begin{array}{l}\text { Lung metastasis; } \\
\text { mortality }\end{array}$ \\
\hline 3 & Left footplate & No metastasis & $\begin{array}{l}\text { Extended resection, } \\
\text { skin grafting }\end{array}$ & 21 & Presence \\
\hline 4 & Left footplate & No metastasis & $\begin{array}{l}\text { Extended resection, } \\
\text { medial pedal flap of footplate }\end{array}$ & 41 & Presence \\
\hline 5 & Right footplate & $\begin{array}{l}\text { Right inguinal lymph } \\
\text { node metastasis }\end{array}$ & $\begin{array}{l}\text { Amputation, right inguinal } \\
\text { lymph node dissection }\end{array}$ & 31 & Presence \\
\hline 6 & Right heel & $\begin{array}{l}\text { Right inguinal lymph } \\
\text { node metastasis }\end{array}$ & $\begin{array}{l}\text { Extended resection, skin } \\
\text { grafting, right inguinal } \\
\text { lymph node dissection }\end{array}$ & 26 & Presence \\
\hline
\end{tabular}

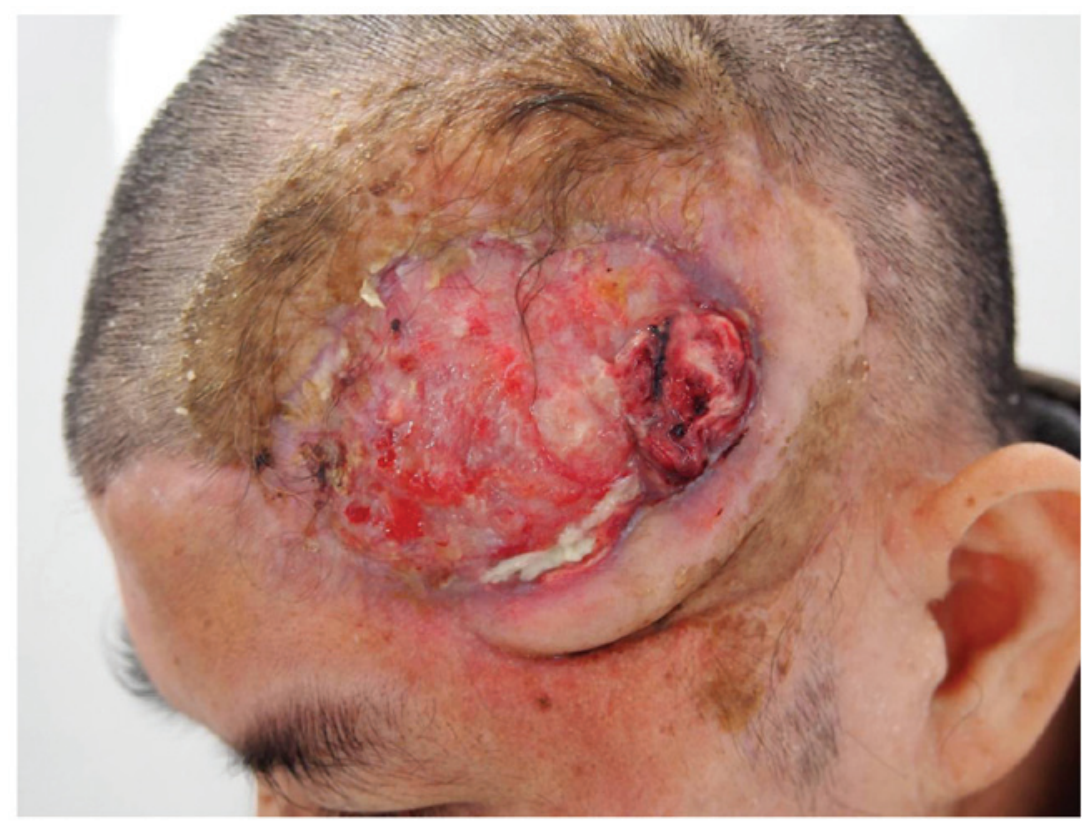

Figure 1. Squamous cell carcinoma arising in an ulcer on the head, showing invasion of the cranium and dura mater.

with squamous cell carcinoma had a regional or sentinel lymph node metastasis rate of $30.23 \%$ and a distant metastasis rate of $11.63 \%$. In patients with squamous cell carcinoma of the lower limb, the rate of sentinel lymph node metastasis was $35.48 \%$ and the rate of distant metastasis was $16.13 \%$. In patients with squamous cell carcinoma of the upper limb, the rate of sentinel lymph node metastasis was $28.57 \%$ and the rate of distant metastasis was $0 \%$. The location of the tumor was strongly associated with the rate of metastasis. Squamous cell carcinoma in the lower limb has previously been reported to have a higher rate of metastasis (20). Among patients with melanoma, $66.67 \%$ had sentinel lymph node metastasis and $33.33 \%$ had distant metastasis.

Squamous cell carcinoma and melanoma are aggressive types of tumor with high rates of metastasis. It is therefore important to detect sentinel lymph node and distant metastases prior to deciding the therapeutic regimen. Patients with sentinel lymph node metastasis should undergo lymph node dissection (21). PET-CT has a high sensitivity for the detection of metastasis and has been reported to be useful for the detection of lymph node metastasis in patients with malignant melanoma (22). Sentinel lymph node biopsy is a relatively non-traumatic method of screening for lymph node metastasis in patients with squamous cell carcinoma-type Marjolin's ulcers (23). In the present study, we were able to identify sentinel lymph node metastasis by detecting areas of increased uptake on PET-CT. However, B-mode ultrasound-guided biopsy and surgical specimen examination findings showed that certain nodes with increased uptake on PET-CT exhibited inflammatory hyperplasia but not metastasis. The reasons for 


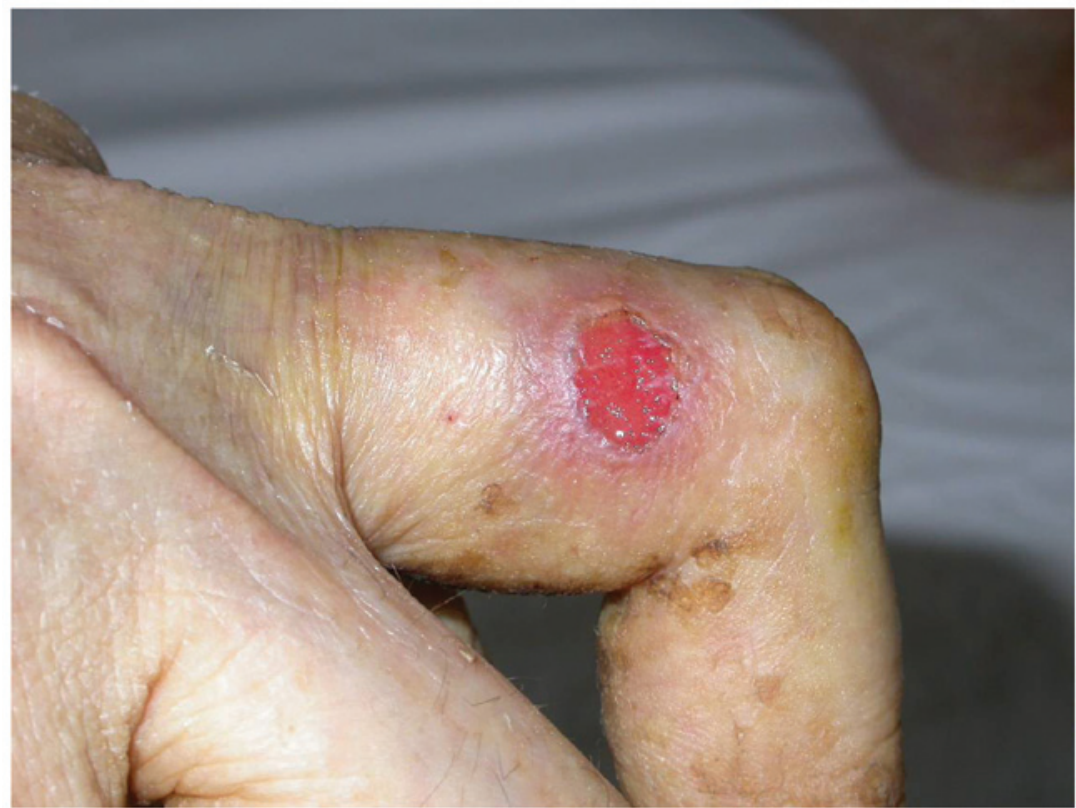

Figure 2. Well-differentiated squamous cell carcinoma arising in an ulcer on the left middle finger.

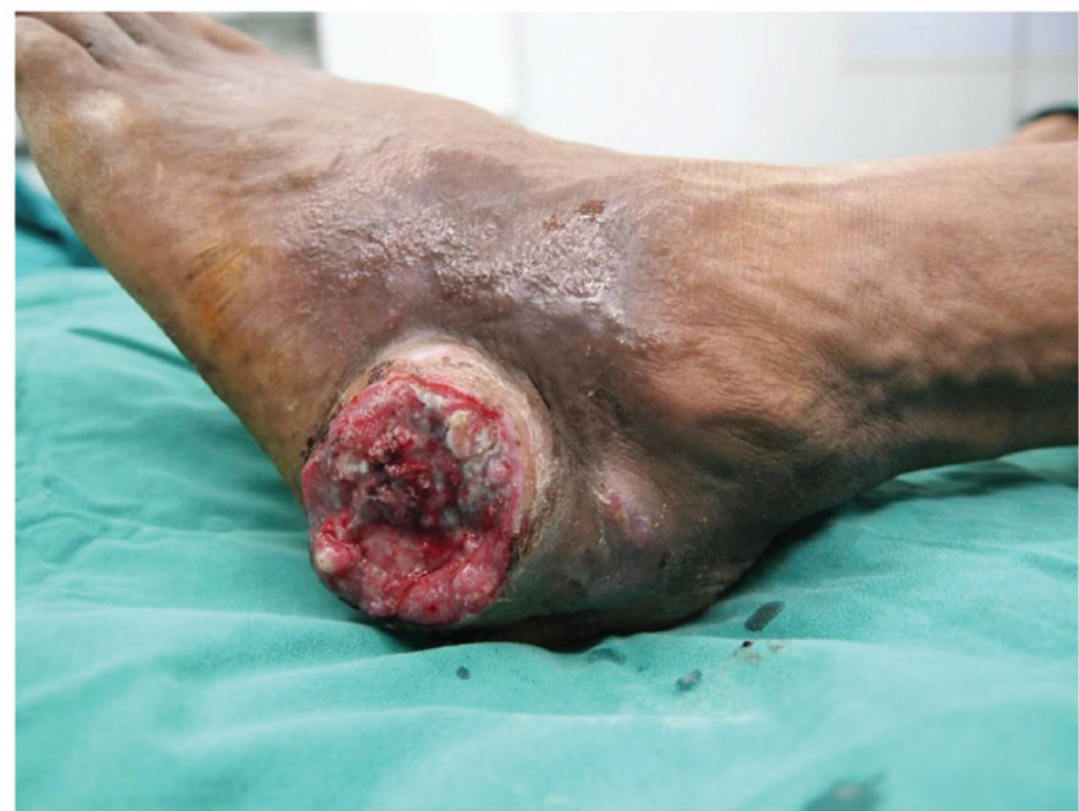

Figure 3. Well-differentiated squamous cell carcinoma arising in an ulcer on the lateral aspect of the left ankle in a patient with simultaneous carcinomatous ulcers on the medial and lateral aspects of the ankle.

this are unclear. PET-CT findings alone are therefore insufficient for the definitive diagnosis of lymph node metastasis, and they should be used in combination with ultrasound-guided biopsy findings. The Affiliated Foshan Hospital started using a Philips Gemini PET-CT scanner (Philips Healthcare, Best, the Netherlands) in February 2004. In the present study, only 11 patients underwent both PET-CT and ultrasound guided biopsy, and the accuracy rate for diagnosis of sentinel lymph node metastasis was $100 \%$ in these patients. Prior to the introduction of PET-CT, patients with suspected sentinel lymph node metastasis underwent B-mode ultrasound and CT examinations, but the findings were less precise than those with PET-CT. Distant metastasis can be detected early using PET-CT alone, and patients with distant metastasis are considered to have unresectable disease.

The pathogenesis of Marjolin's ulcers remains poorly understood. Development of squamous cell carcinoma in burn scar ulcers was reported to be associated with local Fas gene mutation and deletion $(24,25)$. Diagnosis of Marjolin's ulcers depends on the pathological examination of biopsy specimens. Sampling from different sites increases the diagnostic rate (16). Patients with chronic or recurrent skin ulcers that do not heal after several months of conservative treatment should undergo biopsy for early diagnosis. Marjolin's 


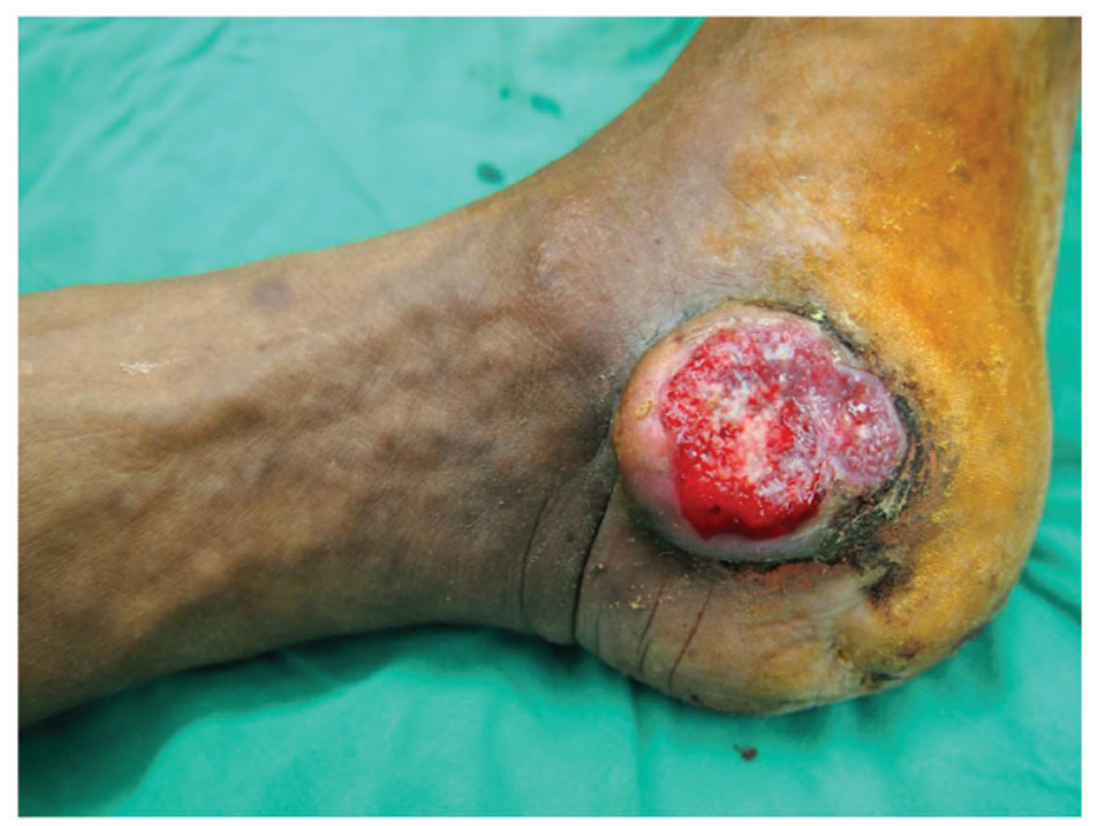

Figure 4. Well-differentiated squamous cell carcinoma arising in an ulcer on the medial aspect of the left ankle of the patient shown in Fig. 3.

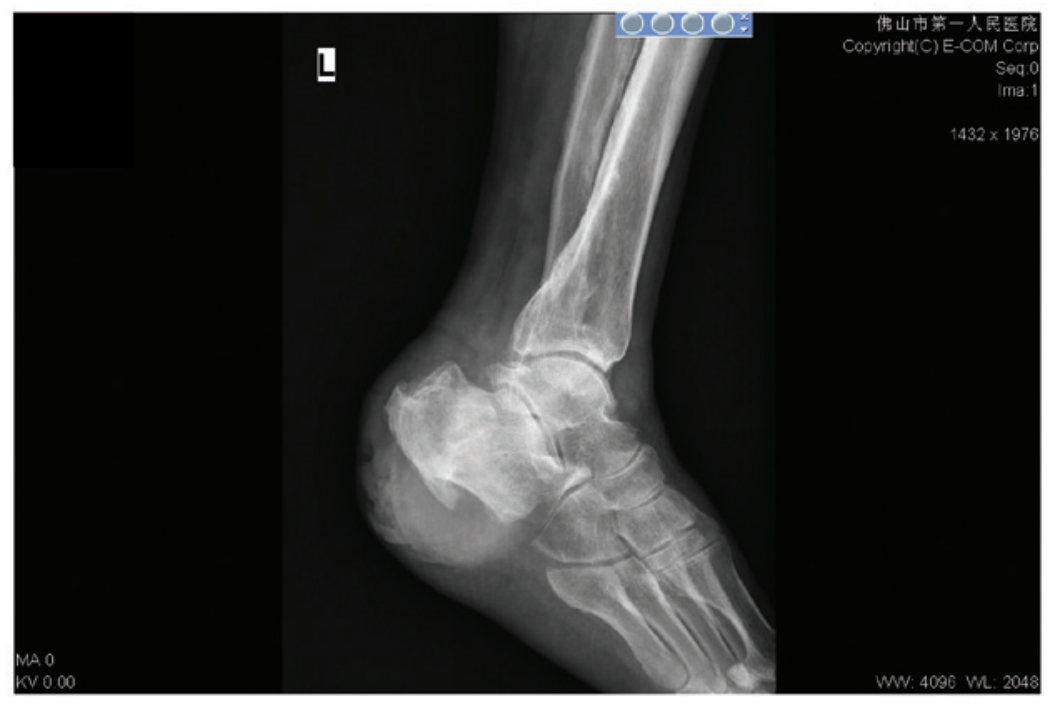

Figure 5. Radiographic findings from the patient shown in Fig. 3, showing bone changes and signs of osteomyelitis.

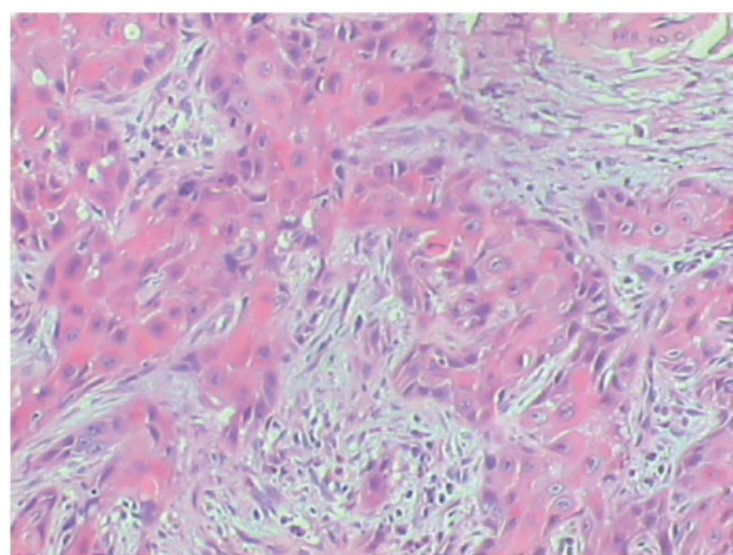

Figure 6. Pathological findings from the patient shown in Fig. 3, showing well-differentiated squamous cell carcinoma (stain, hematoxylin and eosin staining; magnification, $\mathrm{x} 400$ ). ulcers should be treated by extended resection and skin grafting or skin flap repair (26). The resection margin should extend $\geq 2 \mathrm{~cm}$ beyond the edges of the lesion (20). Amputation is necessary when the tumor has invaded the bones, for aggressive tumors and for tumors that cannot otherwise be resected with adequate margins. Sentinel lymph node dissection is required in patients with sentinel lymph node metastasis $(9,20,26)$. Patients with squamous cell carcinoma and sentinel lymph node metastasis can undergo amputation and sentinel lymph node dissection. The present data confirm that squamous cell carcinoma-type Marjolin's ulcers can occur in different regions of the body, but that sentinel lymph node metastasis most commonly occurs in limb lesions, particularly of the lower limb. Patients with limb lesions can therefore be treated by amputation and sentinel lymph node dissection with satisfactory results. 


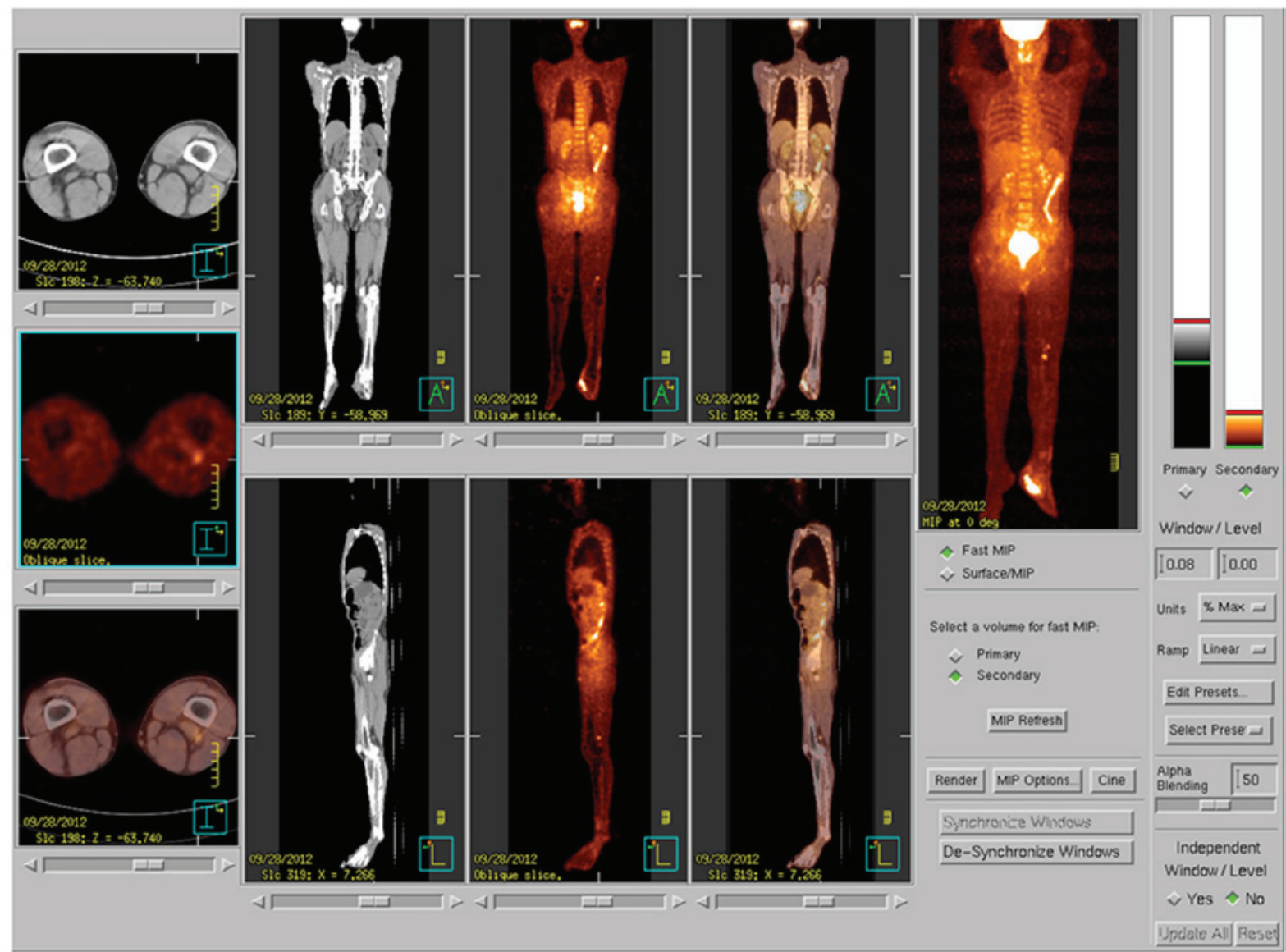

Figure 7. ${ }^{18}$ F-Fluorodeoxyglucose-positron emission tomography findings from the patient shown in Fig. 3, showing increased uptake in the lymph nodes of the left popliteal fossa and left inguinal region.

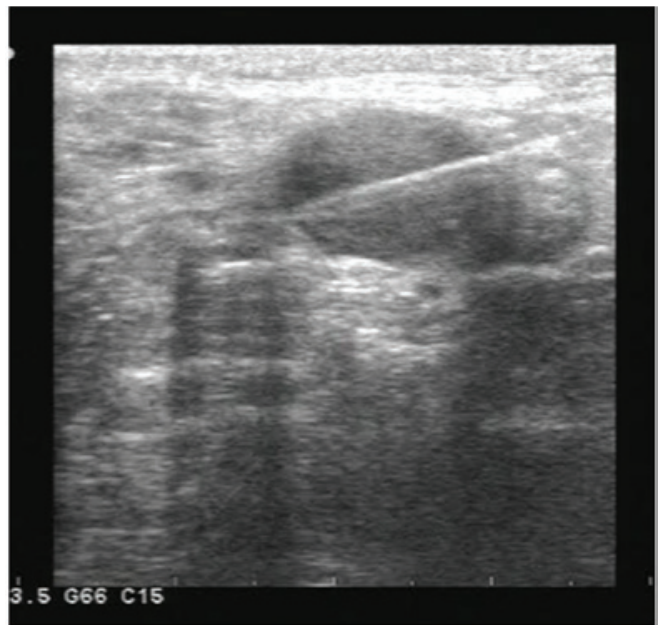

Figure 8. Ultrasound-guided biopsy findings of a left popliteal lymph node in the patient shown in Fig. 3 .

Similar to patients with squamous cell carcinoma, patients with melanoma who do not have metastasis should undergo more extended resection and skin grafting or skin flap repair. Patients with sentinel lymph node metastasis but no distant metastasis should undergo amputation with lymph node dissection. In the present study, all malignant melanoma-type ulcers occurred in the lower limb. However, unlike with squamous cell carcinoma, patients with melanoma and with distant or extensive lymph node metastasis cannot be cured by surgical treatment, and interferon therapy should be considered in these patients, despite its poor curative effects.

There is no evidence that radiotherapy is a successful first-line treatment choice for squamous cell carcinoma. Squamous cell carcinoma in Marjolin's ulcers is usually wellor moderately differentiated, and radiotherapy is therefore not effective $(16,21)$. Radiotherapy may also induce further carcinomatous change. Radiotherapy was therefore not selected as the first treatment choice in any of the patients in this study.

Marjolin's ulcers are preventable. Chronic skinulcers should be actively treated to avoid carcinomatous change $(26,27)$. In this study, the mean patient age was 64.15 years. The majority of the patients had been treated ineffectively with Chinese herbs or other local remedies due to their poor financial circumstances, and some did not receive any treatment. This resulted in chronic ulceration that eventually underwent carcinomatous change. Recently, a new cooperative medical care system has been developed in rural areas of China, and the Urban Employee Medical Insurance system has been established $(28,29)$. Patients with financial restrictions can therefore be treated in hospital, which may help to reduce the incidence of Marjolin's ulcers.

In conclusion, the results of the present study strongly indicate that chronic skin ulcers should be treated as early as possible and carefully followed-up. PET-CT combined with B-mode ultrasound-guided biopsy can precisely detect sentinel 
lymph node metastasis and guide clinical therapy. Patients with squamous cell carcinoma- or melanoma-type Marjolin's ulcers and sentinel lymph node metastasis should undergo amputation and sentinel lymph node dissection, since such tumors predominantly occur in the limb, particularly in the lower limb.

\section{Acknowledgements}

The study was supported by Medical Scientific Research Foundation of Guangdong Province, China (no. A2012637).

\section{References}

1. Steffen C: Marjolin's ulcer. Report of two cases and evidence that Marjolin did not describe cancer arising in scars of burns. Am J Dermatopathol 6: 187-193, 1984.

2. Da Costa JC: III. Carcinomatous changes in an area of chronic ulceration, or Marjolin's ulcer. Ann Surg 37: 496-502, 1903.

3. Nayil K, Hafiz A, Dar H, et al: Kangri cancer invading the brain in a Kashmiri lady (Marjolin ulcer): A case report. Neurosurg Q 22: 69-71, 2012.

4. Fleming MD, Hunt JL, Purdue GF and Sandstad J: Marjolin's ulcer: A review and reevaluation of a difficult problem. J Burn Care Rehabil 11: 460-469, 1990.

5. Wani I: Kangri cancer. Surgery 147: 586-588, 2010.

6. Xie EF, Li AO, Wang SL, et al: Burn scar carcinoma: Case reports and review of the literature. Ann MBC 5: 102, 1992.

7. Eltorai IM, Montroy RE, Kobayashi M, et al: Clinical notes: Marjolin's ulcer in patients with spinal cord injury. J Spinal Cord Med 25: 191-195, 2002.

8. Smith J, Mello LF, Nogueira Neto NC, et al: Malignancy in chronic ulcers and scars of the leg (Marjolin's ulcer): a study of 21 patients. Skeletal Radiol 30: 331-337, 2001.

9. Ozek C, Celik N, Bilkay U, et al: Marjolin's ulcer of scalp: report of fourteen cases and review of the literature. J Burn Care Rehabil 22: 65-72, 2001.

10. Bauer T, David T, Rimareix F, et al: Marjolin's ulcer in chronic osteomyelitic: seven cases and a review of the literature. Rev Chir Orthop Reparatrice Appar Mot 93: 63-71, 2007.

11. Bauk VOZ, Assunção AM, Domingues RF, et al: Marjolin's ulcer: a twelve-case report. An Bras Dermatol 81: 355-358, 2006

12. Schoeman BJ. Squamous cell carcinoma in neuropathic plantar ulcers in leprosy: another example of Marjolin's ulcer. S Afr Med J 86: 966-969, 1996 (In Dutch).
13. Barr LH and Menard JW. Marjolin's ulcer: The LSU experience. Cancer 52: 173-175, 1983.

14. Gül U and Kiliç A. Squamous cell carcinoma developing on burn scar. Ann Plast Surg 56: 406-408, 2006.

15. Copcu E and Culhaci N. Marjolin's ulcer on the nose. Burns 28 : 701-704, 2002.

16. Ozek C, Cankayali R, Bilkay U, et al: Marjolin's ulcers arising in burn scars. J Burn Care Rehabil 22: 384-389, 2001.

17. Kowal-Vern A and Criswell BK. Burn scar neoplasms: a literature review and statistical analysis. Burns 31: 403-413, 2005.

18. Treves N and Pack GT. The development of cancer in burn scars. Surg Gynecol Obstel 51: 749, 1930

19. Novick M, Gard DA, Hardy SB and Spira M: Burn scar carcinoma: a review and analysis of 46 cases. J Trauma 17: 809-817, 1977.

20. Sabin SR, Goldstein G, Rosenthal HG and Haynes KK: Aggressive squamous cell carcinoma originating as a Marjolin's ulcer. Dermatol Surg 30: 229-230, 2004.

21. Ames FC and Hickey RC. Squamous cell carcinoma of the skin of the extremities. Int Adv Surg Oncol 3: 179-199, 1980.

22. Mijnhout GS, Hoekstra OS, van Tulder MW, et al: Systematic review of the diagnostic accuracy of (18)F-fluorodeoxyglucose positron emission tomography in melanoma patients. Cancer 91: $1530-1542,2001$

23. Eastman AL, Erdman WA, Lindberg GM, et al: Sentinel lymph node biopsy identifies occult nodal metastases in patients with Marjolin's ulcer. J Burn Care Rehabil 25: 241-245, 2004.

24. Lee SH, Shin MS, Kim HS, et al: Somatic mutations of Fas (Apo-1/CD95) gene in cutaneous squamous cell carcinoma arising from a burn scar. J Invest Dermatol 114: 122-126, 2000.

25. Baliarsing AS. Will Fas gene help to diagnose burn scar squamous cell carcinoma? Plast Reconstr Surg 108: 575, 2001.

26. Phillips TJ, Salman SM, Bhawan J and Rogers GS: Burn scar carcinoma. Diagnosis and management. Dermatol Surg 24: 561-565, 1998.

27. Spring PM, Myers JN, EI-Naggar AK and Langstein HN: Malignant melanoma arising within a burn scar case report and review of the literature. Ann Otol Rhinol Laryngeol 110: 369-376, 2001.

28. Shi L and Zhang D: China's new rural cooperative medical scheme and underutilization of medical care among adults over 45: Evidence from CHARLS pilot data. J Rural Health 29 (Suppl 1): s51-s61, 2013.

29. Zhou Q, Hong D, Lu J, Zheng D, Ashwani N and Hu S: Pediatric medical care system in China has significantly reduced abandonment of acute lymphoblastic leukemia treatment. J Pediatr Hematol Oncol 37: 181-184, 2015. 